This is an electronic reprint of the original article. This reprint may differ from the original in pagination and typographic detail.

Author(s): Kari, Tuomas; Arjoranta, Jonne; Salo, Markus

Title: Behavior change types with Pokémon GO

Year: $\quad 2017$

Version:

Please cite the original version:

Kari, T., Arjoranta, J., \& Salo, M. (2017). Behavior change types with Pokémon GO. In FDG '17: Proceedings of the International Conference on the Foundations of Digital Games (Article 33). ACM. https://doi.org/10.1145/3102071.3102074

All material supplied via JYX is protected by copyright and other intellectual property rights, and duplication or sale of all or part of any of the repository collections is not permitted, except that material may be duplicated by you for your research use or educational purposes in electronic or print form. You must obtain permission for any other use. Electronic or print copies may not be offered, whether for sale or otherwise to anyone who is not an authorised user. 


\title{
Behavior Change Types with Pokémon GO
}

\author{
Full Paper
}

\author{
Tuomas Kari \\ Faculty of Information Technology, \\ University of Jyvaskyla \\ P.O. Box 35, FI-40014 \\ Finland \\ tuomas.t.kari@jyu.fi
}

\author{
Jonne Arjoranta \\ Department of Music, Art and Culture \\ Studies, University of Jyvaskyla \\ P.O. Box 35, FI-40014 \\ Finland \\ jonne.arjoranta@jyu.fi
}

\author{
Markus Salo \\ Faculty of Information Technology, \\ University of Jyvaskyla \\ P.O. Box 35, FI-40014 \\ Finland \\ markus.t.salo@jyu.fi
}

\begin{abstract}
Digital games are one of the most popular entertainment media in the world. Their allure and widespread popularity makes them an interesting and highly potential platform for behavior change attempts. In this paper, we investigate what types of behavior changes Pokémon GO has promoted or induced among its players. The study is based on an online survey sample of 262 Pokémon GO players, collected using the critical incident technique and analyzed using qualitative methods. The analysis shows that the behavior changes induced by Pokémon GO are not just restricted to increased physical activity or social behavior but are actually much more multifaceted: players were more social, found their routines more meaningful, expressed more positive emotions, and were more motivated to explore their surroundings.
\end{abstract}

\section{CCS CONCEPTS}

- Human-centered computing $\rightarrow$ Mixed / augmented reality - Human-centered computing $\rightarrow$ Ubiquitous and mobile devices - Information systems $\rightarrow$ Massively multiplayer online games

\section{KEYWORDS}

Pokémon GO, digital gaming, critical incident technique, behavior change, augmented reality games, location-based games, exergames, behavior change support system, procedural rhetoric

\section{ACM Reference format:}

T. Kari, J. Arjoranta, M. Salo. 2017. In Proceedings of The International Conference on the Foundations of Digital Games, Cape Cod, Massachusetts USA, August 2017 (FDG'17), 10 pages.

DOI: http://dx.doi.org/10.1145/3102071.3102074

\section{INTRODUCTION}

Implementing different game elements, i.e. the "process of gamification" [1], has become increasingly common in different contexts, for example, health and exercise. The common aim of gamification is to motivate people to behave in desired ways through more gameful and enjoyable user experiences [2], and gamification can be effective in promoting and sustaining healthy behaviors [3]. Different gamification strategies can be applied through novel or existing games [4] and those strategies often share central features with established health behavior change techniques [5]. Thus, it is logical that behavior change strategies could be implemented through games. The allure of digital games and the fact that digital gaming has become one of the most popular entertainment media in the world makes digital games an interesting and highly potential platform for behavior change attempts. From a research perspective, it poses an interesting question: which type of behavior changes could be supported through games or be induced by games.

In this study, we examine the augmented reality game Pokémon GO as a way of enabling behavior change and analyze what types of behavior changes players of the game have experienced. The main research questions of the study are:

1. Can Pokémon GO serve as a behavior change support system?

2. What types of behavior changes has Pokémon GO promoted or induced among the players?

Permission to make digital or hard copies of all or part of this work for personal or classroom use is granted without fee provided that copies are not made or distributed for profit or commercial advantage and that copies bear this notice and the full citation on the first page. Copyrights for components of this work owned by others than the author(s) must be honored. Abstracting with credit is permitted. To copy otherwise, or republish, to post on servers or to redistribute to lists, requires prior specific permission and/or a fee. Request permissions from Permissions@acm.org.

FDG'17, August 14-17, 2017, Hyannis, MA, USA

(C) 2017 Copyright is held by the owner/author(s). Publication rights licensed to ACM.

ACM 978-1-4503-5319-9/17/08...\$15.00

http://dx.doi.org/10.1145/3102071.3102074 
applications [e.g., 7], and services [e.g., 8,9], but to our best knowledge, only one [10] has investigated critical incidents of mobile augmented reality games.

We show that games can promote changes in behavior. Pokémon GO can make players lives more meaningful, enable more social behavior and give them tools to be active in their lives. The results and the derived implications can be valuable for the players, designers, and those public sector parties aiming to influence people's behavior with games.

This study contributes by looking at a variety of different behavior change types in one study, while prior studies have focused on a limited set of behavior change types related to Pokémon GO (e.g., increased physical activity). Thus, we offer a more comprehensive view by identifying several behavior change types enabled by the game. Moreover, our findings are new in a way that we present several behavior changes not empirically identified in prior studies.

\section{BACKGROUND}

\subsection{Augmented Reality / Location-Based Games}

While games are often seen as being tied to living rooms or offices through game consoles or computers, the increasing role of mobile technology in everyday applications means that games, too, spread outside from within the four walls. An early example of this type of game is the location-based game BotFighters [11], where nearby players fought each other's robots by sending text messages from their mobile phones. New technologies for location-awareness (like GPS) and increased processing power have enabled games that are aware of their contexts or that add virtual elements to physical locations (augmented reality or AR).

Games that extend outside their usual frames through augmenting technology or by being played in physical locations are known more generally in the academic literature as pervasive games [12]. Defining features of these kinds of games is that they expand either spatially, temporally or socially beyond usual limits. Spatial expansion means that there are no clear areas of play, while temporal expansion means that there are no clear boundaries between when you are playing or not. Social expansion means that anyone can (potentially) be a player and the game can be played with anyone. We analyze one such game in this article.

\subsection{Pokémon GO}

Pokémon GO [13] is a location-based augmented reality mobile game in which the purpose is to catch Pokémon creatures. The player joins one of three teams and uses the collected Pokémon to battle others in designated battle locations called gyms. The game supports in-app purchases of different game items. Pokémon GO was launched in July 2016 and was rapidly adopted around the globe. According to the market intelligence firm Newzoo [14], the game reached 550 million downloads in first 80 days, and by November 2016, the total download number had surpassed 600 million [15]. However, as is typical for mobile games, after its success had peaked, the download trend turned into decline. In November 2016 the game was downloaded less than 10 million times [16]. The number of players also declined [17]. Nevertheless, according to [16], the game still had millions of players four months after the game was published and has stayed among the most profitable games on Google Play and in the top 100 free apps on iOS (checked January 9, 2017). In total, the game was estimated to have generated $\$ 950$ million in revenue in 2016 [18].

Pokémon GO is based on location-based and augmented reality mechanics. The player navigates around the physical world settings and the player's avatar follows on the game's map based on physical world street maps. Key features of the game map include gyms (locations where the player can train Pokémon or battle with them) and PokéStops (locations where the player can gather game items). When encountering a Pokémon, the player can choose to use the game's AR mechanics to display animated creatures over physical world surroundings on the screen of a mobile device. When playing the game as intended, it requires moving between physical world places and hence requires physical activity from the player [19]. Thus, the gameplay can have a strong exergaming aspect to it. Exergaming is a "form of digital gaming requiring aerobic physical effort exceeding sedentary activity level and including strength-, balance-, or flexibility-related activity - from the player that determines the outcome of the game" [20]. Pokémon GO is largely based on Niantic's earlier location-based game Ingress $[21,22]$. For example, most of the PokéStops are derived from Ingress portals [23] - special physical locations between which the players have to physically move [21].

There are many reasons beyond the Pokémon franchise that contribute to the popularity of Pokémon GO and its success compared to earlier location-based games, for example, social play, critical mass of players, combination of outdoor play and physical activity, and simple enough game mechanics [24]. Our findings suggest that the perceived positive behavior changes are also one component that promotes the playing of Pokémon GO.

The first published studies regarding Pokémon GO have reported on the game's positive influence on physical activity (PA) behavior change [e.g., 22,25,26,27]. However, one study [26] found that the PA increase was not sustained after six weeks. The game has also been suggested to support people to change sedentary indoor behaviors and screen-time to active outdoor time $[27,28]$. Players who would otherwise be sedentary seem to benefit the most from Pokémon GO [29]. Pokémon GO can also have a strong social element to it. It has been suggested to be able to change people's social behavior and help people suffering from severe social withdrawal [30]. [31] also reported about the games potential positive influence on historical and cultural awareness. Some players also travel for the sole purpose of playing the game and are willing to spend money (outside the game) for the purposes of enjoyment and game success [32]. Besides the many reported positive incidents and benefits, there have also been reports of negative incidents taking place whilst playing the game, such as accidents, injuries [33], trespassing, 
and violence [31]. Pokémon GO has also been suggested to have geographically-linked safety risks [34]. Thus, it seems that the game can also lead to the dark side of gaming by changing people's behavior in negative ways. Something, that is obviously important to prevent. Overall, there have been both positive and negative reports and news regarding the game [35].

The main motivation to play Pokémon GO seems to be fun $[10,22]$, though people clearly use the game also to combine fun and exercise [10]. Also, [22] found that game-design elements that allow players to collect new Pokémon persuades them to go out and exercise, and that these elements are also perceived more persuasive than battling challenges. [10] also suggested that for most players, the enjoyment of playing the game is more important than beating their opponents or achieving some goal. [36] investigated the personality characteristics of Pokémon GO players, former players and non-players. They reported that the players are less conscientiousness than non-players, and that "player motivation" is only relevant for adopting the game - not for continuing playing the game. All in all, Pokémon GO has received relatively much interest in academic research, and even a special issue focusing on Pokémon GO was published in Mobile Media \& Communication [37].

\subsection{Behavior Change Support Systems}

According to [38], IT always impacts people's attitudes and behaviors in some ways, and sometimes the impact can even be an unintended side effect due to the design. Various applications for different purposes can be developed to influence behavioral change and this attempted influence can come in many forms, both positive (e.g., supporting a desired behavior change) and negative (e.g., deception or coercion) [38]. [38] defines the concept of behavior change support system (BCSS) and defines one as a "socio-technical information system with psychological and behavioral outcomes designed to form, alter or reinforce attitudes, behaviors or an act of complying without using coercion or deception". Thus, BCSSs emphasize the voluntariness of behavior change outcome.

The form outcome refers to "formulation of a pattern for a situation where one did not exist beforehand". The alter outcome refers to "changes in a person's response to an issue". The reinforce outcome refers to "the reinforcement of current attitudes or behaviors, making them more resistant to change" [38].

With act of complying "the goal of the behavioral change is simply to make sure that the end-user complies with the request of the system". With behaviors the goal is to "elicit a more enduring change than simple compliance once or a few times". With attitudes the goal is to "influence the end-users' attitudes rather than behavior only". Out of these changes, the act of complying is typically the easiest to achieve, behaviors demand more, and the attitude is the most difficult to change. [38]

BCSSs include stakeholders with the intention of impacting someone's attitudes or behavior. There are three types of stakeholders: the ones who create or produce BCSSs, the ones who grant access to or distribute the systems to people, and the individual adopter or user of the systems [38,39]. This study focuses on the last-mentioned, but derives implications also for the other stakeholders.

As is evident from the Pokémon GO example, a game can "work" as a BCSS: a game exposes its players to a variety of game experiences as stimulants that can influence the players' future behavior. While an ideal BCSS persuades its users to adopt the target behavior voluntarily, the change in behavior can also be unintentional [38]. The behavior changes occurring due to playing Pokémon GO can thus be either intentional or unintentional. In other words, a single game can act as a BCSS for some, while others might play the game just for the enjoyment without any purposeful intention towards behavior change - still not excluding a possible occurrence of an unintentional behavior change.

\subsection{Procedural Rhetoric}

In addition to being software potentially changing people's behavior, Pokémon GO is also a game. Game studies has a theoretical approach called procedural rhetoric [40], related to how BCSS understands systems. Procedural rhetoric argues that games (and other procedural systems) have unique ways of presenting arguments and persuading people of them. This is framed in terms of rhetoric, but as in the case of BCSS's, it is a matter of changing people's views of the world and therefore (potentially) affecting their behaviors.

Procedural rhetoric works by presenting a system portraying some other phenomenon. The system encodes some aspects of the phenomenon in a way that presents the phenomenon in a certain way. By interacting with the system, the player (or user) encounters the argument presented by the system and participates in making it. For example, the game September 12th [41] presents a Middle Eastern village with terrorists. The player can shoot the terrorists with missiles, but because they are not accurate, civilians will also be killed by the strikes. When the remaining civilians encounter the bodies of civilians killed in the strikes, they turn into terrorists, perpetuating an endless cycle. The game makes a procedural argument that airstrikes are not an effective tool against terrorism.

Pokémon GO presents the generally beneficial activity of going out for walks as a game of hunting fantastical creatures. The game uses several mechanical means for portraying exercise as a worthwhile effort. In the case of procedural rhetoric, it is less important whether the effect is intended or not.

Both literature on BCSS and procedural rhetoric argue that systems have specific means for changing people's behaviors. Thus, the empirical part of our study examines what types of behavior changes Pokémon GO players have experienced.

\section{METHODOLOGY}

In order to tap into the players' behavior changes, this study followed a qualitative approach. We applied the critical incident technique (CIT) to address users' actual experiences (instead of hypothetical scenarios). CIT is a well-established technique containing "a set of procedures" [6] for collecting, analyzing, and classifying observations of human behavior [42]. CIT allows the 
respondents to describe the actual use experiences in their own words and can thus uncover valuable information about user behaviors [43,44]. A critical incident is defined as a single experience, which a person perceives as unusually positive or negative [45]. Critical incidents are easy to remember and describe and can thus be used to generate a precise and in-depth record of activities [46]. Further benefits of CIT include acquiring reports of the most significant and relevant experiences, which typically are highly influential for human behavior [6]. Overall, several studies [e.g., 42,43] have demonstrated that CIT provides both validity and reliability, and is a suitable method for gaining understanding and insights on an undiscovered phenomenon [47].

To collect the data, we conducted an English language online survey meant for international audience. The data collection took place during a time period of four months from mid-July to midNovember 2016. We created the survey with LimeSurvey 2.05+ software. Before launching the survey, we pretested the questionnaire with ten early adopters of Pokémon GO, based on which some minor modifications were made. During the data collection period, we distributed an invitation to partake in the survey through different discussion forums with varying topics and different social media channels (Twitter, Facebook, and Reddit) in order to reach a wide range of respondents. The respondents were not provided with any rewards for answering. Part of the data collected with the same survey has been previously used in another article focusing on critical incidents of mobile augmented reality games [10].

The questions regarding critical incidents were only asked from the respondents with experience of playing Pokémon GO. To collect the information about the critical incidents, we used an exact wording from prominent critical incident research [e.g., 47,48]: "Think of a time when you had an outstandingly positive or negative experience [with Pokémon GO]", followed by a series of more detailing questions about the positivity/negativity of the incident, and then regarding the experience itself. In line with a common way to use CIT, we asked each respondent to choose and describe one outstanding incident. The survey also included some questions for a purpose of another study. The full question items are available from the authors by request. To ensure the quality of the empirical evidence, we followed guidelines by $[42,48]$ and set criteria for the reported incidents to be included in the analysis: 1) it was required to be a single incident concerning a specific playing session of Pokémon GO with 2) sufficient incident description.

The collected data was qualitatively analyzed [49] using the analysis software Atlas.TI. Suggestions from [50] were also taken into account during analysis. The answers were free-coded by one of the authors. First, all the answers were read, then read again and a set of preliminary codes was formed. These codes were tested on the first 20 answers and revised based on these answers. Then all of the answers were coded, with new codes introduced when the answers did not fit the preliminary codes. Finally, some codes were merged when more general trends were noticed or when codes did not include enough answers in order to be informative. Answers were coded so that quotes could be coded with multiple different codes. After the initial coding, the results were checked by another author before the codes were categorized in more general categories. The categorization resulted in eight categories related to behavior change. These categories are presented separately and used as subheadings in the results-section. Because each quote can be coded with multiple codes, answers can belong to multiple categories. We did not edit the quotes, and they are presented here without corrections.

\section{RESULTS}

In total, our survey received 270 complete responses, out of which 262 met the inclusion criteria to be included in the qualitative analysis. Eight responses were excluded due to insufficient incident description. Out of the reported 262 critical incidents, $205(78.2 \%)$ were positive and $57(21.8 \%)$ were negative. The gender distribution of the sample was tilted toward female respondents with $67.2 \%$ of the respondents being female. The age range of the respondents was from 12 to 64 with the mean age of 28.5 years old. Description of the sample is presented in more detail in Table 1.

\section{Table 1: Description of the Sample}

\begin{tabular}{lcc}
\hline & $\mathrm{n}$ & $\%$ \\
\hline Gender & & \\
\hline Male & 82 & 31.3 \\
Female & 176 & 67.2 \\
Other & 4 & 1.5 \\
\hline Age & & \\
\hline$<20$ years & 26 & 9.9 \\
$20-29$ & 151 & 57.7 \\
$30-39$ & 47 & 17.9 \\
$40 \leq$ years & 38 & 14.5 \\
\hline Household & & \\
\hline One family with kids & 72 & 27.5 \\
One family without kids & 94 & 35.9 \\
Single person & 80 & 30.5 \\
Lone-parent family & 4 & 1.5 \\
Other (e.g. with roommates) & 12 & 4.6 \\
\hline
\end{tabular}

The distribution of critical incident settings is presented in Table 2. As can be seen, most of the incidents $(69.8 \%)$ took place together with others (i.e. not alone). This highlights the social aspect of the game. Almost half of the respondents (43.1\%) had played the game to combine fun and exercise, while a bit over half $(54.6 \%)$ had played just for fun. This indicates the ability of Pokémon GO to make exercise more enjoyable. Most of the incidents $(65.6 \%)$ had taken place in a public setting with permitted access (as perceived by the respondent) or in nature $(20.2 \%)$, while only a small number of incidents had occurred in other surroundings. This shows that the media reports of people wandering to forbidden areas or playing while driving may give a somewhat distorted overall picture as these occurrences are actually quite rare. 
Table 2: Critical Incident Settings

\begin{tabular}{lcc}
\hline & $\mathrm{n}$ & $\%$ \\
\hline Social setting & & \\
\hline Alone & 73 & 27.9 \\
Together with others & 183 & 69.8 \\
N/A & 6 & 2.3 \\
\hline Reason for playing & & \\
\hline Fun & 143 & 54.6 \\
Exercise & 2 & 0.8 \\
Both fun and exercise & 113 & 43.1 \\
N/A & 4 & 1.5 \\
\hline Surrounding setting & & \\
\hline Home & 15 & 5.7 \\
Public setting with & 172 & 65.6 \\
permitted access & & \\
Public setting with & 3 & 1.1 \\
forbidden access & & \\
Nature & 53 & 20.2 \\
Car & 9 & 3.4 \\
Other & 8 & 3.1 \\
N/A & 2 & 0.8 \\
\hline
\end{tabular}

\subsection{Added Activity in Life}

One type of behavior change is increasing general activity and happening in one's life. Several individuals described how their life tended to be rather passive or even "boring" before discovering the game. Indeed, the game provided a longed-for trigger for changing the status quo by departing from everyday routines. Many of such routines took place indoors, at home. Thus, Pokémon GO made the individuals concretely leave their homes and go out. The main characteristics of the game that enable this type of behavior change include setup and start simplicity as well as ubiquitous outdoor features: users could instantly download the game for free and play it in nearly any outdoor surroundings without pre-planning. They also could play only for short bits and continue from where they had previously left. These characteristics were deemed important, because users could easily deviate from their passive lifestyles through short spontaneous efforts - they did not need to schedule for certain time frames or make serious commitments about adding activity in their life. As a specific example, one of the participants described how the game enabled her to build activity into her passive life:

"Prior to [Pokémon GO release], I'd most likely just be chilling at home, exhausted from work. ...the hunt for Pokémon got us out of the house (which is probably where I'd be if not for this game). ...since this game was released, I've spent everyday after work hunting Pokémon in my free time... This has brought back excitement in an otherwise montonomous routine. ...it's sparked a zest for the outside world. It's pretty magical in my opinion." (Participant 1)

\subsection{Enhancing Routines}

For some players playing Pokémon GO did not change previous forms of activity, but added layers of enjoyment or excitement to activities that were part of their daily routines. Most often this related to walking a dog, but Pokémon GO is also played, for example, while on the way to work, buying groceries or traveling. The low time investment and small amount of effort needed to play enables playing the game in small bursts, while doing other activities without overtly disturbing either the main activity or playing. What was central to these players was the ability to play while doing something they were going to do anyway, for example:

"Pokemon Go makes walking from one place to another, for example from home to campus, much more fun." (Participant 2)

Perhaps surprisingly, the game also enhances the routines of non-humans:

"Having grown up playing Pokemon it just feels right to play Pokemon Go. I love that it takes me outside and off of the couch on my days off. Not to mention, my dog loves it too!" (Participant 3)

\subsection{Exploration}

It is obvious that Pokémon GO has made people to go to locations and explore places they do not usually go to. This includes locations in both familiar and unknown surroundings. Some mentioned that the game had made them spend more time in public places, such as parks, and had also noticed the same behavior in the case of many other people. The game can lead people to change their movement patterns and select different routes between places than normally. Some also use the game as a reason or justification to visit new places. The exploration accompanied by the game can lead people to discover new places and things in familiar surroundings as well as completely new areas. The exploration can be either intentional or unintentional. The game also seems to increase awareness of local attractions. People reported that they had discovered previously unknown beautiful or interesting things thanks to PokéStops being located on those particular spots. This kind of discovery was also highly valued.

"I like noticing my surroundings, but for some reason don't do it much just because of it. The game gave me motivation and the extra outside reason to go and walk in new surroundings or see new things in old surroundings, and I liked it." (Participant 4)

"So for the first time I noticed a lot of beautiful and interesting things near my home, like poems in a park and a weird statue." (Participant 4) 


\subsection{Increased Physical Activity}

One central behavior change type induced by Pokémon GO is increased physical activity. A great amount of respondents highlighted how the game had made them to increase their physical activity levels, as illustrated by the following quote:

"I don't really excercise, and this is eztraordinary that I've walked 3-10 kms a day for 3 weeks now." (Participant 5)

Many used the game to combine exercise and playing. It was a way to make exercising more fun and thus worked as a motivator to be physically more active. Some mentioned that the game was the motivator they had been looking for. There seems to be varying physical activity related reasons to play Pokémon GO, and the behavior changes related to physical activity can be either intentional or unintentional. Whereas some used Pokémon GO as a form of exercise, some did not have any exercise related reasons for playing, but rather had noticed that they had been more physically active than before due to playing the game (just for fun). The playing could begin with interest towards the game play, but then continue due to a person realizing how it was also an effective form of exercise.

"I realised that I actually get some exercise while playing the game, yet it doesn't feel like exercising when I play. Even when I walk or run a lot to hatch and catch them." (Participant 6)

Overall, Pokémon GO seems to promote physical activity and thus, change one's physical activity related behavior in a positive way.

\subsection{Strengthening Social Bonds}

While some play Pokémon GO alone, over 2/3 answered playing together with others. Most commonly, this meant playing with friends, but others played with their kids, parents or significant others. For most, it seemed that spending time with somebody important to them was more important than the game itself. Events in the game were made meaningful by being shared with a loved one. One of the strengths of Pokémon GO seems to be that enables spending time with people important to you, while doing something that requires only occasional or partial focus. The game works as social glue, binding people together through shared time and experiences:

"Even though we were playing a digital game, we were still spending time together, walking and laughing and being silly, and seeing other people dot he same." (Participant 7)

"it's saving my marriage since my wife and I finally have something we enjoy together" (Participant 8)
However, this kind of increased social pressure might not always be positive. Everyone would not choose to play if there was no social expectation to do so:

"My friends bully me if I don't play it, so I play it." (Participant 9)

\subsection{Lowering Social Barriers}

"Connecting with strangers is not something that really happens in 2016", one of the answers stated (Participant 10). Yet, people playing Pokémon GO seem to be doing exactly that. Many of the answers highlight how they have met new people and talked to strangers because those strangers were also players. This seemed to bridge generational gaps, as some players noted how people of different ages had interacted because of the game in a way that was unlikely otherwise. Some also mentioned talking to their neighbors for the first time, or getting to know them better, thanks to playing Pokémon GO close to home. The game enables gatherings of people because it is related to concrete, physical locations that form the focal points of play. It also rewards cooperation at those places, since one player placing a lure at a PokéStop also helps other players in the area. This tends to have compounding effects, with groups of players attracting more people. Other mechanics also highlight the social nature of playing, with players choosing a team when they join the game. Other members of that team appear as natural allies, while the other teams are framed as rivals with a common goal, not as enemies. However, not all interaction is desirable, and a small minority of players had felt uncomfortable because of a social interaction with a stranger while playing. However, for most the increased sociability was close to a magical experience:

"-- I love that I can walk around the city, and immediately see other people playing the game, other people enjoying the outdoors and getting some exercise, while making new friends. -- I always regarded the Pokemon shows with some cynicism; everyone was so cheesy and positive and made friends so quickly, based on nothing but their love for pokemon. But now that Pokemon go is released, that really has become the reality. People who have never met before, from opposite backgrounds, that might have walked down the street without ever giving eachother the time of day, can now meet, befriend each other, purely based on their love for Pokemon." (Participant 11)

\subsection{Increased Positive Emotional Expression}

Playing Pokémon GO made some players express their positive emotions more intensively, spontaneously, and openly than usually. According to a recurrent pattern in our data, playing was associated with "happiness" and "positivity" that reflected the excitement shared among the players. These aspects came apparent and concrete, for instance, through a great number of "laughs", "smiles", and "being silly" during the gameplay. What appeared to be rather unique was that such positive expressions 
occurred among strangers in the ordinary physical world settings:

"Because it is not very common to have positive interaction with complete strangers. Spontaneous contact is usually not viewed very positively in Finland but this game has made these kind of moments feel a lot more natural." (Participant 12)

The data indicates that emotional expression was somewhat contagious, since many players emphasized how the pure sight of seeing positive and happy people made them smile. The gameplay also tended to involve continual situations of people approaching others with a positive attitude and offering help. For example, many had experiences of seasoned players approaching beginners to help them with some basic features of the game. One of the players summarized these aspects as follows:

"The good will and positivity of the other players. How we help each other, and the light hearted banter between different teams. There was also a gym there, so we fought over it, and it was a mess but we all were laughing and talking about our strongest Pokémon. Very heart warming." (Participant 13)

\subsection{Self-Treatment}

The game also seems to work as means for self-treatment, i.e. people use Pokémon GO as an instrument to help achieving their goals related to personal wellbeing. In these cases, the game acts as a reason or a tool for behavior change or the subsequent outcome. This often intentional self-treatment can be related to some previously set health or exercise related goal such as weight loss or improving fitness, improving mood, or helping with anxiety or depression. The treatment can be less-serious with people aiming to improve their mood or being happy by playing the game or more-serious with people aiming to improve some physical or mental condition. Overall, people treat physical, mental, and social aspects with the game. As a specific example, one of the participants described how the game had helped with anxiety issues:

"It is really good for motivating me to leave the house, I suffer from depression and the game has been an excellent distraction from the anxiety I sometimes feel when I go out. I play it with my children too, and it's a nice activity to do together which costs nothing." (Participant 14)

Table 3: Frequency of Codes Used in Analysis

\begin{tabular}{ll}
\hline & $\mathrm{n}$ \\
\hline Added activity in life & \\
\hline Break from routine & 12 \\
Going out & 34 \\
Playing alone & 13
\end{tabular}

\begin{tabular}{|c|c|}
\hline Playing as a reward & 1 \\
\hline \multicolumn{2}{|l|}{ Enhancing routines } \\
\hline Dog & 2 \\
\hline $\begin{array}{l}\text { Playing while doing } \\
\text { something else }\end{array}$ & 31 \\
\hline \multicolumn{2}{|l|}{ Exploration } \\
\hline Exploration & 13 \\
\hline Just moved here & 2 \\
\hline Use of public spaces & 3 \\
\hline \multicolumn{2}{|l|}{ Increased physical activity } \\
\hline Exercise & 90 \\
\hline Exergames & 1 \\
\hline \multicolumn{2}{|l|}{ Strengthening social bonds } \\
\hline Playing for somebody else & 1 \\
\hline $\begin{array}{l}\text { Reason for playing: Social } \\
\text { pressure }\end{array}$ & 8 \\
\hline Spending time with family & 45 \\
\hline Spending time with friends & 63 \\
\hline $\begin{array}{l}\text { Spending time with } \\
\text { significant other }\end{array}$ & 26 \\
\hline \multicolumn{2}{|l|}{ Lowering social barriers } \\
\hline Community & 23 \\
\hline Community: online & 6 \\
\hline Competition or $\mathrm{PvP}$ & 14 \\
\hline Groups of people & 36 \\
\hline Making new friends & 14 \\
\hline Meeting neighbors & 4 \\
\hline Meeting new people & 64 \\
\hline Meetup & 3 \\
\hline Negative social experience & 7 \\
\hline $\begin{array}{l}\text { People of different ages } \\
\text { playing or meeting }\end{array}$ & 17 \\
\hline Socialization & 73 \\
\hline $\begin{array}{l}\text { Teaching the game to } \\
\text { others }\end{array}$ & 9 \\
\hline Teams & 15 \\
\hline Teamwork & 12 \\
\hline \multicolumn{2}{|l|}{$\begin{array}{l}\text { Increased positive } \\
\text { emotional expression }\end{array}$} \\
\hline Helping others & 8 \\
\hline $\begin{array}{l}\text { Positive change in other } \\
\text { people }\end{array}$ & 12 \\
\hline Shared excitement/interest & 30 \\
\hline \multicolumn{2}{|l|}{ Self-treatment } \\
\hline $\begin{array}{l}\text { Helps with anxiety or } \\
\text { depression }\end{array}$ & 5 \\
\hline Improved mood & 10 \\
\hline Treatment & 8 \\
\hline
\end{tabular}

\section{DISCUSSION}

The purpose of this study was to examine the augmented reality game Pokémon GO as a BCSS: the ways it can promote behavior change. We analyzed what types of behavior changes players of the game have experienced. The research data was collected from actual players of the game by using the CIT [6]. Following a qualitative approach the data was analyzed by free-coding and categorizing it. 
This study contributes by examining a variety of different behavior change types in one study, while previous research has focused mainly on one or two behavior change types. As such, we offer a more comprehensive view on behavior changes induced by Pokémon GO. Further, we present unique findings regarding several behavior changes not identified in previous research.

Our results demonstrate that Pokémon GO can indeed serve as a BCSS and promote behavior change (RQ1). As suggested by the BCSS literature $[38,51]$, the behavior changes occurring with the game can be both voluntary and intentional or unintentional. The game can also influence behavior on all three levels, as it can form, alter, and reinforce behaviors. This type of influence is identified in game studies as procedural rhetoric [e.g., 40,52]. In contrast to traditional digital games that are sometimes criticized making players passive with their lives, Pokémon GO appears to activate its users in many ways. More precisely, we identified eight types of behavior changes (RQ2): added activity in life, enhancing routines, exploration, increased physical activity, strengthening social bonds, lowering social barriers, increased emotional expression, and self-treatment.

These findings add to current knowledge about the link between games such as Pokémon GO and their players' behavior change. Our findings support the previous findings on the physical [22,25,26,27] and social [30] aspects of Pokémon GO. While these prior Pokémon GO studies have suggested prospective behavior changes that the game could induce, we provide empirical evidence that demonstrated how the game has enabled players to change their behavior in various ways.

One of the central types of behavior changes concerned increased physical activity. We cannot draw conclusions on how long-lasting this behavior change was, but at least in short-term, it is apparent that the game can increase the players' physical activity. This implies that the game could be used as a tool to promote physical activity. Pokémon GO and exergames in general could be utilized by those working with physical activity promotion tasks and also by those individuals who do not otherwise find physical activity and exercise that appealing. A game can be the extrinsic motivator that makes one get up from the couch, go outside, and be physically active.

In popular and media discourse videogames have often been considered conducive to antisocial behavior [e.g., 53]. In contrast, Pokémon GO is very conducive to social interaction, even if playing it does not require social interaction - there are no "onscreen encounters" [23], but it can work as a "social catalyst" [54]. Our analysis shows that it does so in two ways: by creating community-building social encounters between strangers and strengthening bonds between friends and family members. This supports previous findings [55].

Our study shows that the behavior changes induced by Pokémon GO are not just restricted to physical activity or social behavior but actually are much more multifaceted as our findings demonstrate:

First, Pokémon GO can change people's movement behavior, i.e. make them visit new places and select new routes, and thus, increase their exploration of different sites. The subsequent discovery of new and interesting places is highly valued. Therefore, the developers of these kinds of games and systems could benefit from such design decisions that lead players to visit interesting places. Making the gaming area as big as feasible would also increase the chances of discovery. Pokémon GO could also be utilized as a tour/city guide, as it often leads its players to visit sites with cultural value or other significance. Similar games leading people to historical and cultural sites and providing information about those could also be used in education.

Second, one of the strengths of Pokémon GO seems to be related to how it enables people to spend time, whether it is with people close to them, strangers or alone while walking the dog. The low amount of effort needed to play leaves room for doing other things while playing, making the overall experience more enjoyable. This change might not be particularly visible to outsiders, but for the person experiencing the change the increased meaningfulness seems considerable.

Third, the game enabled players to increase their expressions of positive emotions and enthusiasm. The positive expressions appeared to be contagious and link with the game characteristics and dynamics: the players reported increasing positive expressions when the game gathered more and more people to engage in positive activities in shared locations. Many laughs and smiles were shared because the game supports friendly collaboration (e.g., sharing a lure) and does not require rivalry. Thus, game developers could take advantage of such findings by carefully designing activities that can be shared among the players without making them confront each other.

Fourth, as people have realized the different ways they have changed their behavior due to the game, they have also embraced the possibility of using the game as a form of selftreatment or a tool for such. In these cases, the game acts as an instrument to help achieve different goals related to personal wellbeing. This implies that different digital games also on a more general level could be designed, deployed, and used for such self-treatment purposes.

Overall, Pokémon GO made the players' lives more meaningful, enabled more social behavior, and gave them tools to be more active in their lives. We suggest that these perceived positive behavior changes can also be one central component behind the popularity of Pokémon GO.

\section{CONCLUSIONS}

In summary, we have conducted a study on the types of behavior changes Pokémon GO has promoted or induced among its players. The data, collected from 262 Pokémon GO players with an online survey, was analyzed using qualitative methods. We identify eight types of behavior changes: added activity in life, enhancing routines, exploration, increased physical activity, strengthening social bonds, lowering social barriers, increased emotional expression, and self-treatment. To summarize: The behavior changes induced by Pokémon GO are not just restricted to increased physical activity or social behavior but are actually much more multifaceted: players were more social, found their 
routines more meaningful, expressed more positive emotions, and were more motivated to explore their surroundings.

\section{LIMITATIONS AND FUTURE RESEARCH}

There are few notable limitations to this study. Our chosen method of data collection, an online survey, naturally has the limitation of only being able to reach those who have internet access. However, as data connection is required to play Pokémon GO, the lack of internet access most probably did not rule out any potential respondents. Another limitation concerning reaching respondents is that only those players following the discussion forums or social media channels used to distribute the survey were likely to be reached. To mitigate this limitation, we aimed to distribute the survey widely. Additionally, it is apparent that the respondents themselves also spread the invitation to other channels. However, it is clear that the answers are not a global sample, but the data is geographically skewed. For example, Finland is clearly overrepresented. This might also affect the kinds of experiences detailed in the answers. Unfortunately, our data does not allow closer examination of the respondents' countries. Using a survey also prevented us from asking any follow-up questions, for example, regarding who were the others the game was played with. Regarding CIT, it captures the extremes of respondents' positive and negative experiences without paying attention to ordinary experiences. However, we believe that the discovered behavior changes are applicable to ordinary experiences even if the frequencies of the behavior changes are not fully generalizable. Also, the respondents reported more positive than negative incidents. There can be several reasons for this, including the entertainment purpose and hype of Pokémon GO, individuals' potential tendency to report positive experiences about games, and positive attitude towards games in general.

Our study derives also suggestions for future research. First, players' behavior changes could be traced back to the specific characteristics and features of the game. Thus, we suggest researchers to examine the potential links between the game characteristics and different types of behavior change. For example, some game characteristics might enable different types of behavior change than others. Second, our study revealed many behavior changes, but did not distinguish short-term changes from long-term changes. Thus, researchers could utilize longitudinal approaches to study how permanent these behavior changes are and how favorable long-term changes could be achieved. Third, some aspects could be investigated in more detail by using other data collection methods, such as interviews.

\section{ACKNOWLEDGMENTS}

This study has been partially funded by Tekes, and is a part of the research project Hybrid Social Play: Solutions for Future Social Games and Media.

\section{REFERENCES}

[1] T. Kari, J. Piippo, L. Frank, M. Makkonen, and P. Moilanen. 2016. To gamify or not to gamify? Gamification in exercise applications and its role in impacting exercise motivation. In Proceedings of the 29th Bled eConference "Digital economy" Research Volume. University of Maribor, Bled, Slovenia, 393-405.

[2] S. Deterding, S. L. Björk, L. E. Nacke, D. Dixon, and E. Lawley. 2013. Designing gamification: Creating gameful and playful experiences. In Proceedings of the CHI'13 Extended Abstracts on Human Factors in Computing Systems. ACM, Paris, France, 3263-3266.

[3] E. A. Edwards, J. Lumsden, C. Rivas, L. Steed, L. A. Edwards, A. Thiyagarajan, ... and S. Taylor. 2016. Gamification for health promotion: systematic review of behavior change techniques in smartphone apps. Brit. Med. 7. Open 6, 10 (2016), e012447.

[4] T. Alahäivälä, and H. Oinas-Kukkonen. 2016. Understanding persuasion contexts in health gamification: A systematic analysis of gamified health behavior change support systems literature. Int. F. Med. Inform. Advance online publication (2016).

[5] B. Cugelman. 2013. Gamification: what it is and why it matters to digital health behavior change developers. F. Med. Internet Res. Serious Games 1, 1 (2013), e3.

[6] J.C. Flanagan. 1954 The critical incident technique. Psychol. Bull. 51, 4 (1954), 327-358.

[7] M. Salo, and L. Frank. 2017. User behaviors after critical mobile application incidents: the relationship with situational context. Inform. Syst. f. 27, 1 (2017) 5-30.

[8] J. Gummerus, and M. Pihlström. 2011. Context and mobile services' value-inuse. F. Retail. Cons. Ser. 18, 6 (2011), 521-533.

[9] M. Salo, T. Olsson, M. Makkonen, A. Hautamäki, and L. Frank. 2013. Consumer value of camera-based mobile interaction with the real world. Perv. Mob. Comput. 9, 2 (2013), 258-268.

[10] T. Kari. 2016. Pokémon GO 2016: exploring situational contexts of critical incidents in augmented reality. F. Vir. World Res. 9, 3 (2016), 1-12.

[11] It's Alive!. 2001. BotFighters.

[12] M. Montola 2005. Exploring the Edge of the Magic Circle: Defining Pervasive Games. In DAC 2005 Conference. IT University of Copenhagen, Copenhagen, Denmark, 103-106.

[13] Niantic, Inc. 2016. Pokémon GO. Retrieved January 15, 2017 from http://www.pokemongo.com/

[14] Newzoo. 2016. Analysis of Pokémon GO: a success two decades in the making. $\begin{array}{lllll}\text { Retrieved } & \text { February } & 1, & 2017 & \text { from }\end{array}$ https://newzoo.com/insights/articles/analysis-pokemon-go/

[15] Kotaku. 2016. Pokemon GO Hits 600 Million Downloads. Retrieved February 2, 2017 from http://www.kotaku.com.au/2016/11/pokemon-go-hits-600million-downloads/

[16] BBC. 2016. Pokemon Go update seeks to revive interest. Retrieved February 9 , 2017 from http://www.bbc.com/news/technology-38291993

[17] SurveyMonkey Inc. 2016. Pokémon GO retention: No, it's not facing a player loyalty crisis. Retrieved February 2, 2017 from https://www.surveymonkey .com/business/intelligence/pokemon-go-retention/

[18] Venturebeat. 2017. Pokémon Go generated revenues of $\$ 950$ million in 2016 Retrieved February 10, 2017 from http://venturebeat.com/2017/01/17 pokemon-go-generated-revenues-of-950-million-in-2016/

[19] T. Baranowski. 2016. Pokémon Go, go, go, gone?. Games Health f. 5, 5 (2016), 293-294.

[20] T. Kari, and M. Makkonen. 2014. Explaining the usage intentions of exergames. In Proceedings of the 35th International Conference on Information Systems 2014. (ICIS), AIS, Auckland, New Zealand, 18 pages.

[21] Niantic, Inc. 2016. Ingress. The game. Retrieved May 16, 2017 from https://www.ingress.com/

[22] A. Meschtscherjakov, S. Trösterer, A Lupp, and M. Tscheligi. 2017. Pokémon WALK: Persuasive effects of Pokémon GO game-design elements. In International Conference on Persuasive Technology. Springer, Amsterdam, Netherlands, 241-252.

[23] A. de Souza e Silva. 2016. Pokemon Go as an HRG: Mobility, sociability, and surveillance in hybrid spaces. Mob. Media Commun. 5, 1 (2016), 20-23.

[24] J. Paavilainen, H. Korhonen, K. Alha, J. Stenros, E. Koskinen, and F. Mayra 2017. The Pokémon GO experience: A location-based augmented reality mobile game goes mainstream. In Proceedings of the 2017 CHI Conference on Human Factors in Computing Systems (CHI '17). ACM, New York, NY, 24932498.

[25] T. Althoff, R. W. White, and E. Horvitz. 2016. Influence of Pokémon Go on physical activity: study and implications. F. Med. Internet Res. 18, 12 (2016), e315.

[26] K. B. Howe, C. Suharlim, P. Ueda, D. Howe, I. Kawachi, and E. B. Rimm. 2016. Gotta catch'em all! Pokémon GO and physical activity among young adults: difference in differences study. Brit. Med. F. 355, (2016), i6270.

[27] C. R. Nigg, D. J. Mateo, and J. An. 2017. Pokémon Go may increase physical activity and decrease sedentary behaviors. Ame. f. Pub. Health. 107, 1 (2017), 37-38.

[28] A. G. LeBlanc, and J. P. Chaput. 2016. Pokémon Go: A game changer for the physical inactivity crisis?. Prev. Med. Advance online publication (2016).

[29] F. Y. Wong. 2017. Influence of Pokémon Go on physical activity levels of university players: a cross-sectional study. Int. F. Health Geogr, 16, 8 (2017), 12 
pages.

[30] M. Tateno, N. Skokauskas, T. A. Kato, A. R. Teo, and A. P. Guerrero. 2016. New game software (Pokémon Go) may help youth with severe social withdrawal, hikikomori. Psychiat. Res. 246, (2016), 848-849.

[31] M. Serino, K. Cordrey, L. McLaughlin, and R. L. Milanaik. 2016. Pokémon Go and augmented virtual reality games: a cautionary commentary for parents and pediatricians. Curr. Opin. Pediatr. 28, 5 (2016), 673-677.

[32] F. J. Zach, and I. P. Tussyadiah. 2017. To catch them all-The (un) intended consequences of Pokémon GO on mobility, consumption, and wellbeing. In Information and Communication Technologies in Tourism 2017, Roland Schegg and Brigitte Stangl (Eds.). Springer International Publishing: London, 217-227.

[33] B. Joseph, and D. G. Armstrong. 2016. Potential perils of peri-Pokémon perambulation: the dark reality of augmented reality?. Ox. Med. Rep. 2016, 10 (2016), omw080.

[34] A. Colley, J. Thebault-Spieker, A. Y. Lin, D. Degraen, B. Fischman, J. Häkkilä, K. Kuehl, ... and J. Schöning. 2017. The geography of Pokémon GO: Beneficial and problematic effects on places and movement. In Proceedings of the 2017 CHI Conference on Human Factors in Computing Systems (CHI '17). ACM, New York, NY, 1179-1192.

[35] M. McCartney. 2016. Game on for Pokémon Go. Brit. Med. f. 354, i4306 (2016), $1-2$.

[36] E. Mattheiss, C. Hochleitner, M. Busch, R. Orji, and M. Tscheligi. 2017. Deconstructing Pokémon Go-An empirical study on player personality characteristics. In International Conference on Persuasive Technology. Springer, Amsterdam, Netherlands, 83-94.

[37] Larissa Hjorth (ed.). 2017. Special section: Pokémon GO: Playful phoneurs and the politics of digital wayfarers. Mob. Media Commun. 5, 1 (Jan. 2017).

[38] H Oinas-Kukkonen. 2013. A foundation for the study of behavior change support systems. Pers. Ubiquit. Comput. 17, 6 (2013), 1223-1235.

[39] BJ Fogg. 2003. Persuasive Technology Using Computers to Change What We Think and Do. Morgan Kaufmann: San Francisco, CA.

[40] Ian Bogost. 2007. Persuasive Games: The Expressive Power of Videogames. MIT Press, Cambridge, UK.

[41] Newsgaming.com. 2003. September 12th: A Toy World. Retrieved January 20 2017 from http://www.newsgaming .com/games/index12.htm.

[42] D. D. Gremler. 2004. The critical incident technique in service research. F. Serv. Res. 7, 1 (2004), 65-89.

[43] B. Andersson, and S. Nilsson. 1964. Studies in the reliability and validity of the critical incident technique. f. Appl. Psychol. 48, 6 (1964), 398-403.

[44] J. Gogan, M. D. McLaughlin, and D. Thomas. 2014. Critical incident technique in the basket. In Proceedings of the 35th International Conference on Information Systems 2014 (ICIS). AIS, Auckland, New Zealand, 18 pages.

[45] B. Edvardsson, and I. Roos. 2001. Critical incident techniques: towards a framework for analyzing the criticality of critical incidents. Int. F. Serv. Ind. Manag. 12, 3 (2001), 251-268.

[46] S.J. Grove, and R. P. Fisk. 1997. The impact of other customers on service experiences: a critical incident examination of "getting along". f. Retailing 73, 1 (1997), 63-85

[47] M. L. Meuter, A. L. Ostrom, R. I. Roundtree, and M. J. Bitner. 2000. Self-service technologies: understanding customer satisfaction with technology-based service encounters. 7 Marketing 64, 3 (2000), 50-64.

[48] M. J. Bitner, B. H. Booms, and M. S. Tetreault. 1990. The service encounter: diagnosing favorable and unfavorable incidents. F. Marketing 54, 1 (1990), 7184.

[49] Guest, G., MacQueen, K. and Namey, E. 2012. Applied Thematic Analysis. SAGE Publications, Inc.

[50] Kathy Charmaz. 2014. Constructing Grounded Theory (2nd. ed.). Sage, London, UK.

[51] M. Oduor, T. Alahäivälä, and H. Oinas-Kukkonen. 2014. Persuasive software design patterns for social influence. Pers. Ubiquit. Comput. 18, 7 (2014), 16891704 .

[52] M. Treanor, M. Michael, and N. Wardrip-fruin. 2010. 'Kaboom! Is a ManySplendored Thing: An Interpretation and Design Methodology for MessageDriven Games Using Graphical Logics'. In Proceedings of the Fifth International Conference on the Foundations of Digital Games (FDG). ACM, Monterey, CA, 224-231.

[53] D. Williams. 2003. The Video Game Lightning Rod. Inform. Commun. Soc. 6, 4 (2003), 523-550.

[54] L. Humphreys. 2016. Involvement shield or social catalyst: Thoughts on sociospatial practice of Pokémon GO. Mob. Media Commun. 5, 1 (2016), 15-19.

[55] C. C. Yang, and D. Liu. 2017. Motives matter: motives for playing Pokémon Go and implications for well-being. Cyberpsych. Beh. Soc. N. 20, 1 (2017), 52-57. 